\title{
ЛАЗЕРНЫЙ СПЕКТРОМЕТР ЭЛАНИК ЛЕГКО ОТКРОЕТ ТАЙНУ МЕТАЛЛА
}

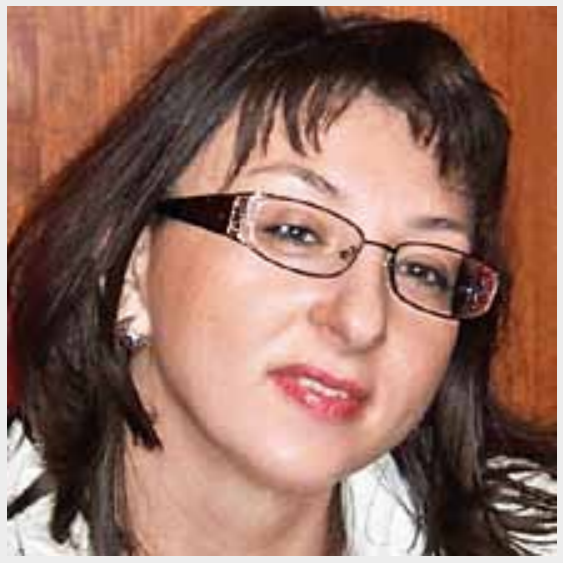

Группа компаний "ЛАЗЕР-КОМПАКТ" - ведущий российский экспортер собственной лазерной продукции (более 50 тысяч штук лазеров поставлено в 42 стран мира). Основная доля продукции компании продана в США, Германию и Францию, ощутимую долю в объеме продаж имеют Япония, Южная Корея, Великобритания и Тайвань. Основателем группы "ЛАЗЕР-КОМПАКТ" является Иван Иванович Куратев, выпускник МФТИ факультета физической и квантовой электроники, доктор физико-математических наук, автор более 100 научных статей и изобретений в области лазерной техники. Компания "Лазер-экспорт", входящая в группу "ЛАЗЕРКОМПАКТ", ежегодно выпускает на лазерный рынок новые модели DPSS-лазеров с параметрами на уровне лучших мировых достижений. Однако теперь компания осваивает новые рынки, связанные с металлообработкой. Об этом ведет рассказ Екатерина Федына, заместитель директора компании "Лазер-экспорт" по маркетингу.

Екатерина, компания "Лазер-компакт" известна специалистам как производитель твердотельных лазеров с диодной накачкой (DPSS-лазеров), поставщик излучателей на мировой лазерный рынок. С каким изделием вы выступаете на выставке "Металлообработка-2019»?

Компания "Лазер-экспорт" (главная компания группы "ЛАЗЕР-КОМПАКТ" в настоящее время) представляет лазер ный спектрометр ЭЛАНИК - первый ручной анализатор элементного состава металлов и сплавов. Прибор способен измерять концентрацию углерода (до 0,01\%) в сталях и чугунах без использования инертного газа. Лазерный спектрометр ЭЛАНИК внесен в Государственный реестр средств измерений Российской Федерации под номером 70911-18.

Когда состоялась премьера показа прибора?

Прибор мы выпустили два года назад, в 2017 году мы показали его на выставке "Металлообработка-2017». Тогда еще лазерный анализатор проходил процесс испытаний и не был внесён в реестр средств измерений. Мы хотели узнать горизонт его потенциальных возможно- стей и потому выступили на непрофильной для нас выставке (наша профильная выставка по лазерной продукции всегда была "Фотоника"). По заинтересованности посетителей мы почувствовали, в анализе каких веществ и каких метрологических параметрах нуждаются потенциальные заказчики. Сейчас ЭЛАНИК - это уже утвержденное средство измерения, что очень важно для потребителей, так как они могут использовать прибор для подтверждения марок используемых в их производстве заготовок и комплектующих. Зачастую такая информация нужна при проведении промышленной экспертизы объектов, а также на входном контроле металлов и материалов на любых предприятиях, которые используют в своем производстве металл, в том числе и для проверки химического состава мишеней для изготовления оптических покрытий.

Какая связь между вашими лазерными компетенциями и анализатором металлов и сплавов?

ЭЛАНИК базируется, прежде всего, на основном инновационном узле анализатора - лазере, являющемся ноу- 
хау группы компаний "Лазер-экспорт". Принцип действия прибора основан на методе лазерно-искровой эмиссионной спектрометрии (ЛИЭС). Впервые явление было продемонстрировано в 1962 году на рубиновом лазере. Метод лазерной эмиссионной спектроскопии LIBS (LaserInduced Breakdown Spectroscopy) заключается в том, что при облучении образца сфокусированным мощным короткоимпульсным лазерным излучением происходит нагревание и испарение вещества, образуется плазма, эмиссионный спектр которой и регистрируется. По спектру излучения можно определять элементный состав исследуемого образца. Метод позволяет проводить анализ всех элементов, в том числе легких ( $\mathrm{Li}, \mathrm{Be}, \mathrm{B}$, С и др.), без предварительной пробоподготовки на любом материале.

На практике при использовании подобных анализаторов на основе LIBS-технологии наибольшую сложность представляет проблема градуировки прибора. ЭЛАНИК обеспечивает наилучшую точность измерений среди имеющихся сегодня на рынке портативных LIBS-анализаторов и является единственным в мире прибором, который может делать анализ углерода без аргона наряду с другими элементами с погрешностью в несколько сотых процента, учитывая, что углерод является наиболее важным элементом в «черных" сталях. Сердцем ЭЛАНИКа является лазерный источник, производимый компанией "Лазер-экспорт". Для наилучшей точности измерений и стабильной работы прибора очень важно уметь управлять параметрами лазера, который является инструментом создания плазмы, спектр которой мы в итоге анализируем. Для анализа используется несколько спектральных линий от каждого вещества, а также уникальный алгоритм обработки данных спектра, позволяющий сделать количественный анализ более точным и значительно снизить систематические погрешности измерений.

Отличительными чертами прибора является низкий предел обнаружения легких элементов (бериллия, магния, кремния, алюминия, углерода и многих других), отсутствие рентгеновского излучения и связанных с ним ограничений; проведение измерений на воздухе без использования инертного газа (аргона) и других расходных материалов; автоматическое определение вида сплава без участия пользователя; простота использования, удобство (ведь вес ЭЛАНИКа около 2 кг); возможность экспресс-определения химического состава анализируемого вещества.

Какова область применения лазерного спектрометра ЭЛАНИК?

В основном прибор применяют при определении концентрации углерода и других элементов в углеродистых сталях, низколегированных и среднелегированных сталях и сплавов. Предел обнаружения для углерода - до 0,01\%. Использование ЭЛАНИКа в этой области обусловлено тем, что портативные рентгенофлуоресцентные анализаторы, которые давно применяются для анализа химического состава, "не видят" легкие элементы и, главное, углерод. А он очень важен, ведь сталь, как известно, это сплав железа с углеродом.

Также лазерный спектрометр ЭЛАНИК широко используется при анализе высоколегированных сталей и цветных металлов. Прибор незаменим при входном кон-

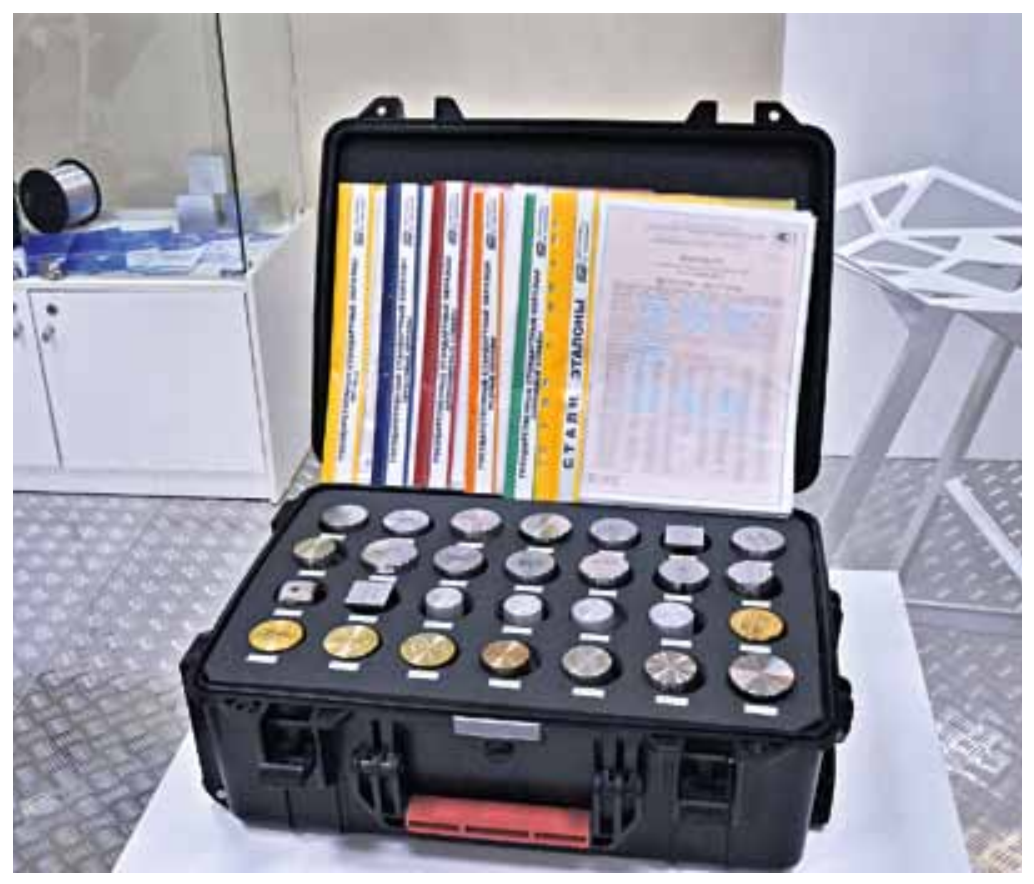




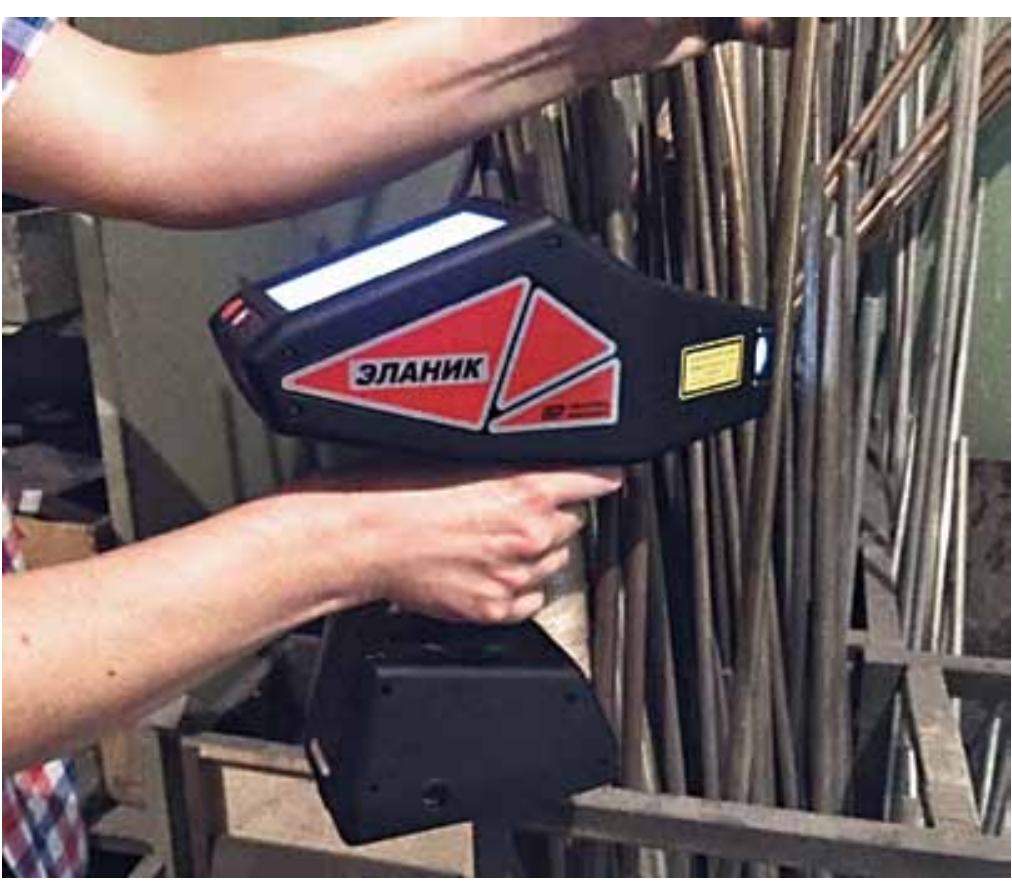

троле сплавов для подтверждения марок металла на основе железа, алюминия, меди, титана, никеля, олова; востребован при сортировке металлов и сплавов, при переработке лома. Одним из важнейших применений прибора также является химический анализ материалов при ремонте и обслуживании трубопроводов, контроль химического состава сварного шва и т.д. Так как химический анализ, особенно концентрация углерода, имеет большое значение при сварке и термообработке - это еще одно из применений ЭЛАНИКа.

Что в имени тебе моем?... Что означает имя ЭЛАНИК?

Основателем группы «ЛАЗЕРКОМПАКТ" и директором компании ООО "Лазер-экспорт" является Иван Иванович Куратев, а прибор называется элементный лазерный анализатор. Сложите пазл, получится ЭЛАНИК.

Со дня премьеры прошло два года. По реальному рынку вы чувствуете, что прибор нужен пользователям?

Да, конечно, спрос есть: одним пользователям нужно подтвердить, что металл, полученный от поставщика, соответ ствует паспорту при поставке. У других крупных предприятий на складе много лет хранится куча металла, на который потеряна документация и отсутствует маркировка, необходимо провести его сортировку по маркам. Кроме того, мы имеем опыт поставки и использования ЭЛАНИКа в таких компаниях, как "Транснефть" - в 2018 мы выиграли тендер и поставили партию приборов для различных дочерних обществ компании. Там наши приборы работают в непрерывном режиме, в полевых условиях на трубопроводах и объектах, практически без выходных и должны соответствовать высоким требованиям надежности. Кроме того, их изначальным требованием была работа прибора при минусовых температурах, и все приборы, поставленные в "Транснефть", оснащены опцией работы при пониженной температуре (до - $20{ }^{\circ} \mathrm{C}$ ). Для подтверждения соответствия данному требованию их специалисты до заказа проводили собственные испытания прибора.

Сейчас спрос превышает предложение, и мы принимаем заказы на октябрь. Наше производство находится в Москве, мы продолжаем его развивать и планируем в следующем году удвоить выпуск приборов.

По вашему опыту, исследования состава каких материалов востребованы больше всего?

Наш прибор может градуироваться на несколько аналитических основ, и цена прибора зависит от количества основ, градуировку на которые мы в него заложили. Сейчас мы можем сказать, что основные запросы идут по составам сталей и чугунов, цветные металлы тоже пользуются спросом, но значительно реже.

По какому образцовому средству измерения вы ведете градуировку производимых лазерных спектрометров?

Градуировку компания "ЛАЗЕР-КОМПАКТ» выполняет на стандартных образцах металлов и сплавов, которые мы закупаем у нескольких организаций. В России это ЗАО «Институт стандартных образцов" в Екатеринбурге, организация выпускает стандартные образцы ферросплавов, чугунов, сталей, сплавов прецизионных, 
сплавов на железоникелевой и никелевой основе, металлургических шлаков. У ООО "Виктори-Стандарт", тоже в Екатеринбурге покупаем стандартные образцы состава цветных металлов и сплавов. Также используем импортные эталоны для задач определения химического состава импортируемых материалов.

То есть метрологическая аттестация вашего прибора не требует поверки по какому-то образцовому средству измерения и достаточно поверки по стандартным образцам?

Прибор ЭЛАНИК - утвержденный тип средства измерения, прошел тестовые испытания в ФБУ "Ростест-Москва", внесен в Госреестры СИ РФ, Беларуси и Казахстана. Это значит - есть метрологический сертификат (свидетельство об утверждении типа СИ), описание типа средства измерения, где записаны метрологические характеристики прибора, предель- ные допустимые погрешности. Каждый выпускаемый нами прибор проходит испытания на подтверждение метрологических характеристик. Для этого нам достаточно сверить полученные результаты с паспортными значениями стандартных образцов.

Для заказчиков, которые хотят использовать наш прибор как средство измерения, мы заказываем и проходим первичную поверку каждого прибора в Ростесте. И уже потребитель, имея сертификат на этот прибор при поставке (в него входит протокол поверки, свидетельство о первичной поверке и свидетельство о том, что лазерный спектрометр ЭЛАНИК внесен в Госреестр), использует наш прибор как средство измерения.

Какое направление развития выбрала компания "Лазер-компакт»?

Мы продолжаем выпускать импульсные и непрерывные лазеры. Твердотель-

\section{ОЛАНИК ${ }^{\circledR}$ \\ Элементный Лазерный Анализатор}

\section{Внесён в Госреестр СИ РФ под номером 70911-18}

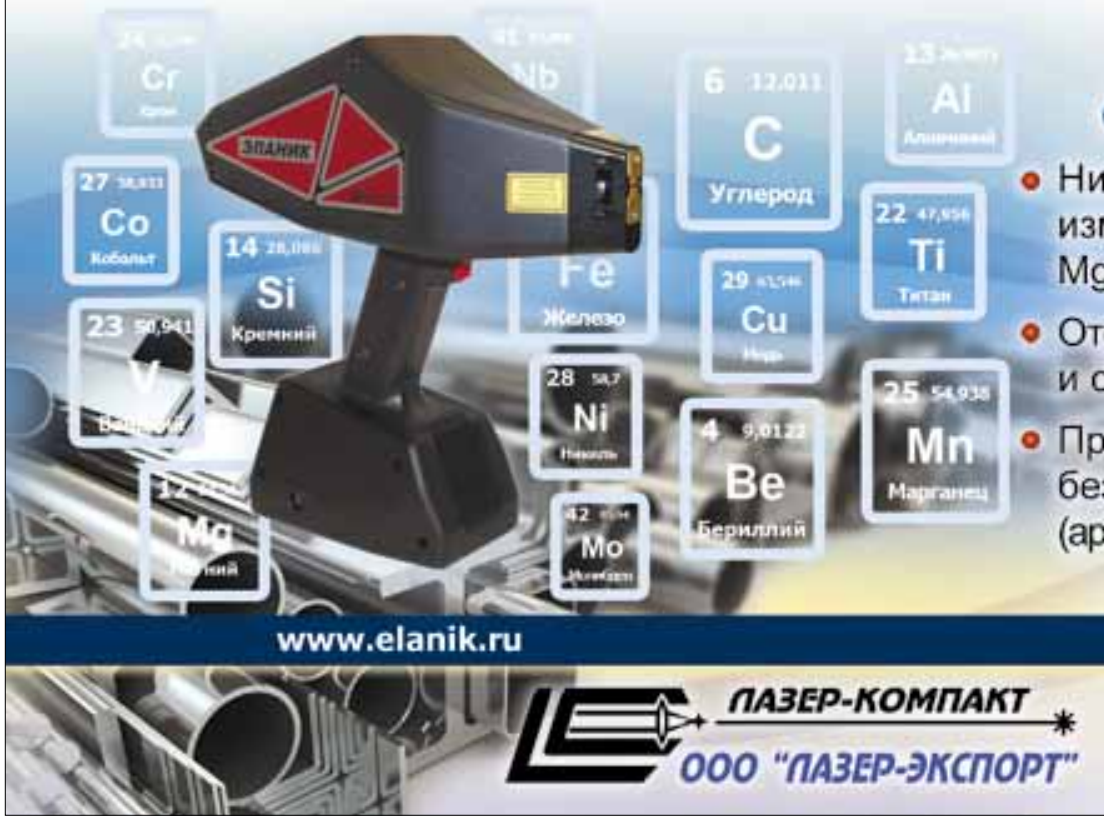

\section{Отличительные черты:}

- Низкие пределы обнаружения при измерении лёгких элементов (Be, C, Mg и др.)

Отсутствие ренттеновского излучения и связанных с ним ограничений.

Проведение измерений на воздухе, без использования инертного газа (аргона) и других расходных материалов.

\section{www.laser-compact.ru}

Ten.: +7 (499) 578-05-48 / Фaxc: +7 (499) 578-05-49 E-mail: sales@laser-export.com

117342 , r. Москва, ул. Введенского, А. 3, корп. 8 


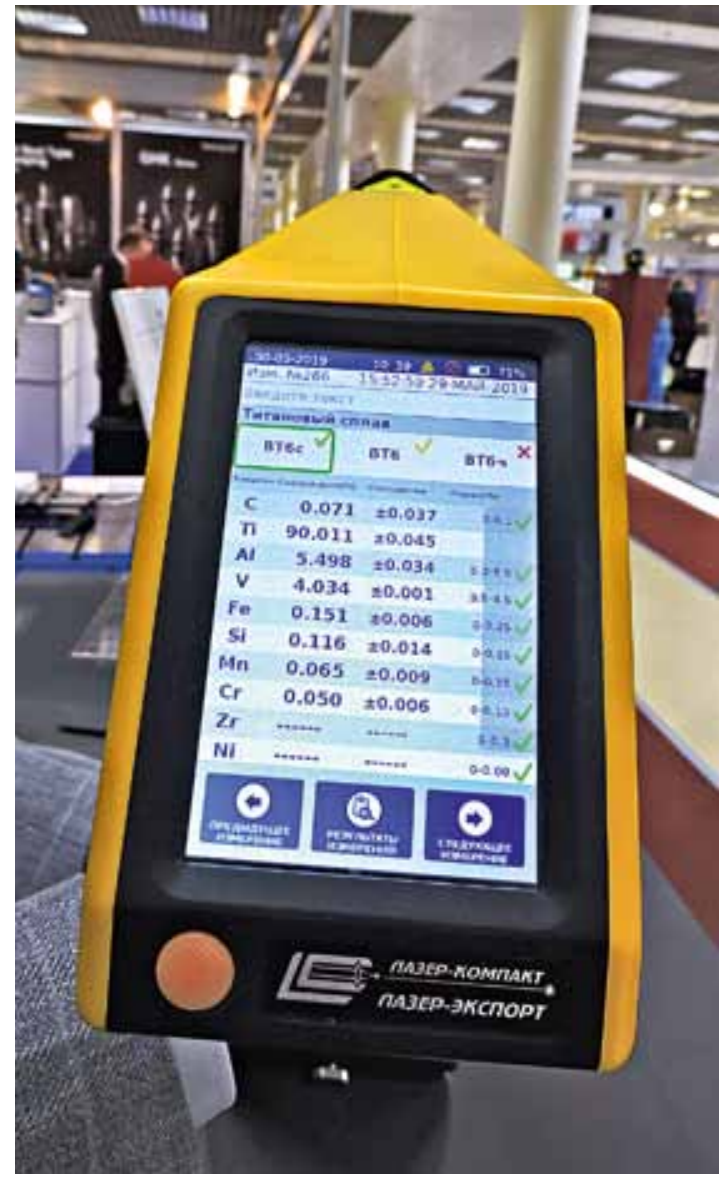

ные лазеры с диодной накачкой - наша специализация. Другой вопрос, что мы сейчас меньше развиваем это направление: очень сложно распределять силы. Когда мы внесли наш лазерный анализатор в Госреестр, круг потребителей значительно расширился. Сейчас приоритетный проект - ЭЛАНИК, то есть

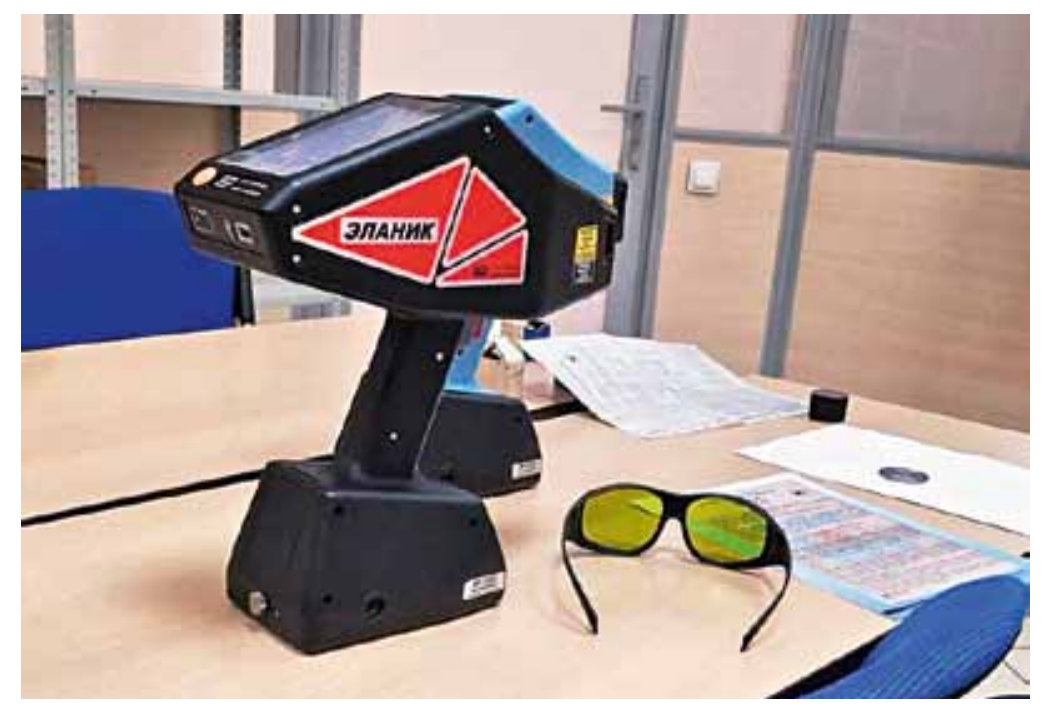

направление лазерных анализаторов элементного состава веществ и материалов. Задач в этой области огромное разнообразие, хватит надолго. Начали мы с металлов и сплавов... Наша конечная цель - массовый прибор для элементного анализа материалов, который будет использоваться повсеместно, на каждом предприятии. В настоящее время массовое применение ограничивается лишь ценой, но мы видим возможность значительного ее снижения в будущем.

Что показывает анализ российского рынка портативных анализаторов химического состава?

Не думаю, что этот рынок сейчас серьезно развивается в России. Тут больше заметна другая тенденция. С точки зрения портативного химического анализа, у нас есть конкуренты - это рентгенофлуоресцентные портативные анализаторы, которые уже давно присутствуют на рынке. Но эти приборы в основном импортного производства, и у них существуют ограничения по определению концентрации легких элементов, они не могут измерять концентрацию углерода - это мы все знаем. Наш прибор не только способен определить легкие элементы, но даже перекрывает диапазон измерений рентгенофлуоресцентных портативных анализаторов. Кроме того, анализаторы с рентгеновским излучением требуют регистрации и лицензии от Роспотребнадзора, так как используют источники ионизирующего излучения (ИИИ). Для лазерных анализаторов это не нужно.

Вы не рассматриваете экспортный вариант?

Мы планируем выход на зарубежные рынки. Но сначала мы хотим насытить внутренний рынок. Для выхода на экспорт нам необходимо сделать предварительную работу по адаптации прибора под зарубежные стандарты стали, чугуна и других сплавов, обеспечить там сервис, сертификацию и т.д.

Есть ли спрос на ваш прибор со стороны рынка аддитивных технологий, 
где к используемым порошкам предъявляют требования не только по размеру, но и по составу?

Спрос есть, но предварительно порошки нужно прессовать или спекать. У нас был удачный опыт работы с компанией "Лазеры и аппаратура ТМ" из Зеленограда, которая как раз занимается аддитивными технологиями. На механические свойства металла влияет не только химический состав, но и режимы термообработки. Спектр потенциальных рынков, интересных для нашей продукции, очень широкий. Это и определение состава транспортных трубопроводов для анализа и ремонта, так как при ремонте трубопроводов при сварке важно знать концентрацию углерода. Для использования прибора в жестких климатических условиях разработана опция работы при низких температурах и термочехол, прибор работает при температурах от $-20{ }^{\circ} \mathrm{C}$ до $+40^{\circ} \mathrm{C}$.

Это и определение состава мишеней метод LIBS оставляет очень маленький дефект. На самом деле это практически не разрушающий метод, то есть остается пятнышко, кратер диаметром менее 200 мкм и глубиной в зависимости от материала порядка нескольких десятков микрометров. На стали глубина кратера будет поменьше, порядка 40-60 мкм, на алюминии кратер будет побольше.

Вы работаете самостоятельно или через дилерские компании?

Лазерный анализатор - это немножко новая для нас область. Компания "Лазерэкспорт" активно использует дилерскую сеть. Среди них "Объединенная сварочная компания", Москва, ООО «Глобалтест» (Беларусь) и другие.

Вы обращаетесь за помощью в какие-нибудь фонды?

На выставке "Металлообработка" мы участвуем через Московский фонд помощи малым и средним предприятиям. Компанию "Лазер-экспорт» отобрали по результатам конкурса проектов. Наш стенд финансируется в рамках экспозиции "Сделано в Москве - Моспром". И мы очень благодарны Московскому фонду, потому что это один из немногих случаев нашей долгой истории (а компании 27 лет), когда нам действительно помогли.

Какие выставки вам помогают в развитии вашего бизнеса?

Естественно, это лазерная выставка "Фотоника", наша профильная выставка. В последнее время мы стали больше участвовать (в том числе с нашими дилерами) в выставках, направленных на потенциальных потребителей ЭЛАНИКа "Металл-экспо", выставки по неразрушающему контролю "Территория NDT», "NDT Russia" и др. Что касается "Металлообработки", то здесь получается еще один целевой рынок, интересный с точки зрения продаж анализаторов химического состава, - как раз здесь мы находим заказчиков, которым прибор ЭЛАНИК необходим для входного контроля.

Желаем вашей компании успехов и процветания!

СЕ. Федына беседовали

Н. Истомина и Л. Карякина

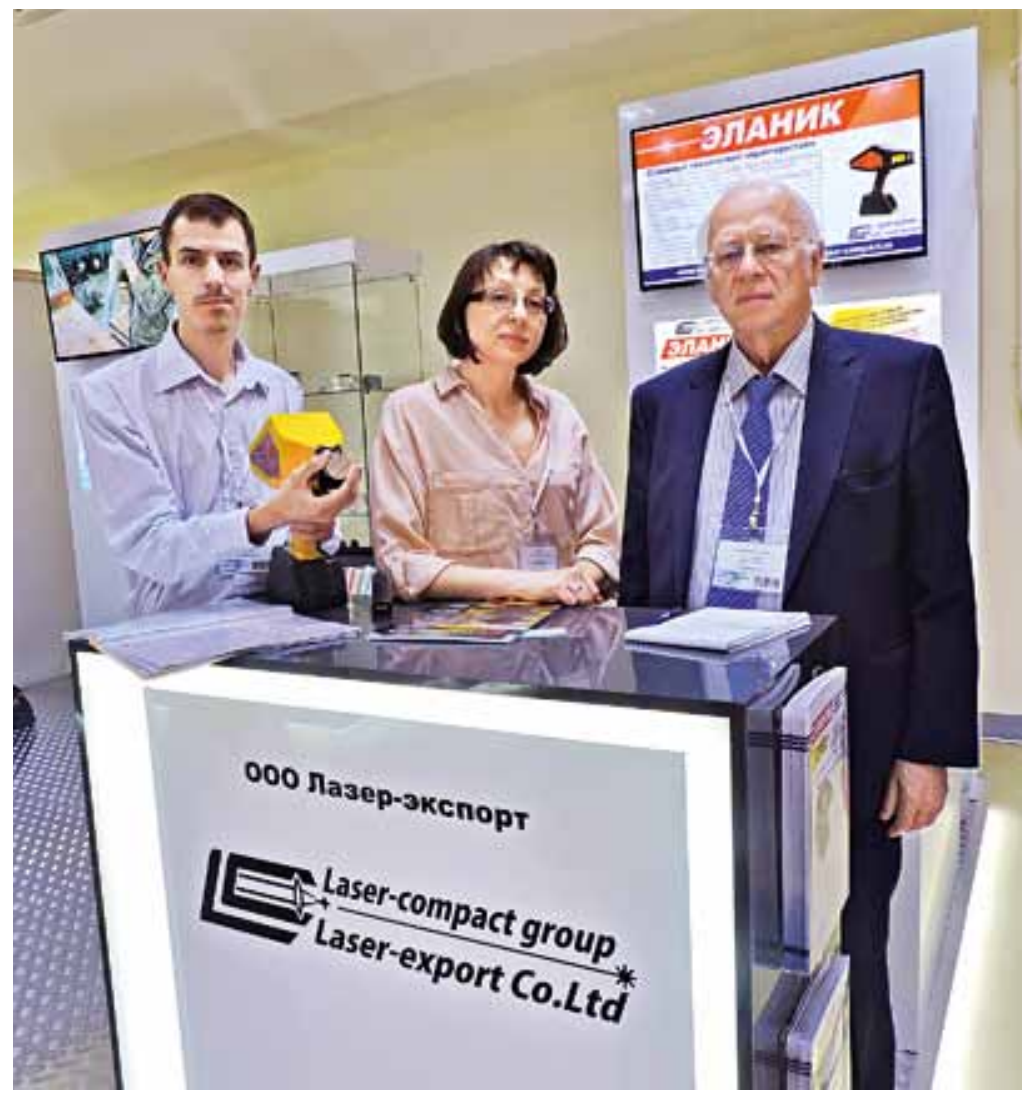

